\title{
Reversion to the Neurovilurent Genome Sequence of Polio Vaccine Virus Isolated from Community-Acquired Meningitis
}

\author{
Zenichiro Kato ${ }^{*}, 1,2,3$, Yasushi Shimada ${ }^{4}$, Hiroaki Ishiko ${ }^{4}$ and Naomi Kondo ${ }^{1,2,3}$ \\ ${ }^{1}$ Department of Pediatrics, Graduate School of Medicine, Gifu University, Yanagido 1-1, Gifu 501-1194, Japan \\ ${ }^{2}$ Center for Emerging Infectious Diseases, Gifu University, 1-1 Yanagido, Gifu 501-1194, Japan \\ ${ }^{3}$ Center for Advanced Drug Research, Gifu University, 1-1 Yanagido, Gifu 501-1194, Japan \\ ${ }^{4}$ Research \& Development Department, Mitsubishi Kagaku Bio-Clinical Laboratories, Inc., Tokyo, Japan
}

\begin{abstract}
Neurologic complication associated with the use of live attenuated oral poliomyelitis vaccine is uncommon, but vaccine-associated paralytic poliomyelitis in recipients or contacts has sometimes been reported. We report here a community-acquired aseptic meningitis case and the genetic investigation of the isolated poliovirus type 2 . The results of the genetic analysis indicate that the mechanism of this meningitis could be the result of the reversion of the virus during replication in the other vaccine recipients, suggesting a quest for revising the current vaccination program.
\end{abstract}

Keywords: Poliovirus, vaccine, meningitis, genetic reversion, neurovirulence.

\section{INTRODUCTION}

Neurologic complication associated with the use of live attenuated oral poliomyelitis vaccine is uncommon, but vaccine-associated paralytic poliomyelitis (VAPP) in recipients or contacts sometimes has been reported every year [1]. We report here a community-acquired aseptic meningitis case and the genetic investigation of the isolated poliovirus type 2 [2].

\section{CASE REPORT}

A healthy 9-year-old boy developed high fever, severe headache and nausea. Next day, he was admitted to our hospital with a provisional diagnosis of aseptic meningitis. His temperature was $37.9{ }^{\circ} \mathrm{C}$ and neck stiffness and Kerning's sign were positive. The leukocyte count was $12,700 / \mathrm{mm} 3$ and CRP was negative. Cerebrospinal fluid (CSF) analysis revealed leukocyte count of $114 / \mathrm{mm}^{3}$ (90\% lymphocytes and $10 \%$ monocytes), protein value $48 \mathrm{mg} / \mathrm{dl}$, glucose level of 57 $\mathrm{mg} / \mathrm{dl}$; and a negative Gram stain. Bacterial culture of CSF was negative. The patient was relieved from symptoms and meningial signs disappeared on the 2nd day. Second CSF examination on the $5^{\text {th }}$ day of the illness revealed leukocyte count of $111 / \mathrm{mm}^{3}$ (99\% lymphocytes and $1 \%$ monocots), protein value $16.8 \mathrm{mg} / \mathrm{dl}$; and glucose level $66 \mathrm{mg} / \mathrm{dl}$. Cranial computed tomography (CT) did not reveal any abnormality. Serum immunoglobulin levels were normal. The patient never demonstrated any evidence of paralytic disease or other neurologic squaele of poliovirus infection.

Virus culture of CSF was done with Hep-2, primary Rhesus monkey kidney, and W-1-38 cell. Neutralization with type-specific antisera revealed that the isolate was type

*Address correspondence to this author at the Department of Pediatrics, Graduate School of Medicine, Gifu University, Yanagido 1-1, Gifu 5011194, Japan; Tel: +81-58-230-6386; Fax: +81-58-230-6387;

E-mail: zen-k@gifu-u.ac.jp
2 poliovirus. Viral RNA was extracted from 250 microliters of sample. After RNA extraction, complementary DNA was synthesized from the resuspended RNA using Moloney murine leukemia virus reverse transcriptase. The complementary DNA product was amplified using PCR and the products were gel-isolated, purified, and sequenced on an automated DNA sequencer using a fluorescent dideoxychain terminator (3-5). We compared the obtained partial sequence of the 5, non-coding region (nt84-544) of the isolated poliovirus with the published sequence of Sabin 2 strain [2]. It revealed a substitution from adenine to guanine at position 481 that is related to the virulence of type 2 poliovirus [3-5].

\section{DISCUSSION}

Our patient had meningitis caused by vaccine-associated strain of type 2 poliovirus, although he had been immunized previously with oral polio vaccine. However, he was not a direct recipient of polio vaccine or immunocompromised host when he had this illness, and he had no discernible contact with the polio vaccine recipients. The virulenceassociated nucleotide change of the isolated virus was revealed by our genetic analysis of the isolate. This indicates that the mechanism of this meningitis could have resulted from the reversion of the virus during replication in the other vaccine recipients [6-9]. Ozawa et al. [10] reported acute disseminated encephalomyelitis (ADEM) associated with polio vaccine due to neurovilurent mutations of the virus. The several nucleotide changes observed in this strain and our strain could be the candidates for the research of the genetic basis of the poliovirus virulence.

The oral live polio vaccines (OPV) have been widely used in many countries including Japan and USA, but in Western European countries, inactivated polio vaccine (IPV) has been used instead of OPV or combined with the following OPV. The Advisory Committee on Immunization Practices of the Centers for Disease Control and Prevention in the USA also has a recommendation regarding the advantages of 
IPV, because IPV may cause only 2 days of fever with no neurologic complications (1). Nevertheless, the OPV has certain advantages as follows: 1) OPV is more easily administered than IPV, 2) OPV confers humoral and serum immunity by infecting the gastrointestinal epithelial cells, and 3) children immunized with OPV can spread infection to nonimmunized persons and provide herd immunity [1, 11]. However, the third advantage itself can cause the serious disadvantages, as observed in the reported cases and our patient, due to the easiness of the reversion of the genome sequences of the vaccine virus [11]. The vaccination program should be discussed considering these issues to establish a better immunization strategy regarding polio vaccines.

\section{REFERENCES}

[1] Committee on Infectious Diseases. Poliomyelitis prevention: recommendations for use of inactivated poliovirus vaccine and live oral poliovirus vaccine. Pediatrics 1997; 99: 300-5.

[2] Totoda H, Kohara M, Kataoka Y, et al. Complete nucleotide sequences of all three poliovirus serotype genomes. Implication for genetic relationship, gene function and antigenic determinants. J Mol Biol 1984; 174: 561-85.

[3] Abraham R, Minor P, Dunn G, Modlin JF, Ogra PL. Shedding of virulent poliovirus revertants during immunization with oral polio- virus vaccine after prior immunization with inactivated polio vaccine. J Infect Dis 1993; 168: 1105-09.

[4] Kammerer U, Kunkel B, Korn K. Nested PCR for specific detection and rapid identification of human Picornaviruses. J Clin Microbiol 1994; 32: 285-91.

[5] Evans DMA, Dunnn G, Minor PD, et al. A single nucleotide change in the 5 ' non-coding region of the Sabin type 3 poliovaccine is associated with increased neurovirulence. Nature 1985; 314: 548-50.

[6] Guiterrez K, Abzug MJ. Vaccine-associated poliovirus meningitis in children with ventriculoperitoneal shunts. J Pediatr 1990; 117 424-27.

[7] Rantala H, Uhari M, Tuokko H, Stenvik M, Kinnunen L. Poliovaccine virus in the cerebrospinal fluid after oral polio vaccination. J Infect 1989; 19: 173-76.

[8] Prevots DR, Sutter RW, Strebel PM, Weibel RE, Cochi SL. Completeness of reporting for paralytic poliomyelitis, United States, 1980 throgh 1991. Implications for estimating the risk of vaccineasociated disease. Arch Pediatr Adolesc Med 1994; 148: 479-85.

[9] Ogra PL, Faden HS, Abraham R, Duffy LC, Sun M, Minor PD Effect of prior immunity on the shedding of virulent revertant virus in feces after oral immunization with live attenuated poliovirus vaccines. J Infect Dis 1991; 164: 191-94.

[10] Ozawa H, Noma S, Yoshida Y, Sekine H, Hashimoto T. Acute disseminated encephalomyelitis associated with poliomyelitis vaccine. Pediatr Neurol 2000; 23(2): 177-9.

[11] Fenichel GM. Neurologic complications of immunization. In: Swaiman K, Ashwal S, Eds. Pediatric Neurology, $3^{\text {rd }}$ ed. St. Louis, Missouri: Mosby Inc 1999; pp. 1470-73. 